\title{
The Reality of Using Smart Devices by the Public Lower Primary School Students: Advantages, Disadvantages and Strategies for Reducing the Extent of using Them
}

\author{
Esra'a Monqeth Mohammad Al - Dabouki and Prof: Natheer Sihan Mohammad Abu Nair
}

\begin{abstract}
The present study aimed to explore the extent of using smart devices by the public lower primary school students. It aimed to explore the extent of spread of smart devices among the public lower primary school students. Questionnaire forms were distributed to 384 public lower primary school students to be answered by their parents. Thus, the sample consists from 384 parents. A descriptive inferential approach was adopted. It was found that the attitudes of the people surrounding the students towards using smart devices by students are positive. It was found that the extent of spread of smart devices among the public lower primary school students is high. It was found that the family's attitudes towards using smart devices by students are positive. It was found that the extent of using smart devices by the public lower primary school students is moderate.
\end{abstract}

Keywords: Smart Devices, advantages, disadvantages and strategies

DOI: $10.7176 / \mathrm{JEP} / 11-4-14$

Publication date: February $29^{\text {th }} 2020$

\section{The Study's Background}

Massive developments have occurred in the field of communication. In addition, an information revolution has been experienced. Such revolution led to the invention of modern technologies. These technologies play a significant role in promoting knowledge. Media and educational institutions today use various means of communication and smart devices in order to promote knowledge. All people today can't stop using technology in all areas, especially in the educational areas.

People today use modern technologies to communicate with others. They use technologies to deliver messages and promote information. The development of technologies reduced the extent of having face to face communication. That is because people became capable of communicating through using internet, mobile phones, smart devices and etc.. However, the use of such technologies has negative impacts in health, social, and psychological areas. They have negative impacts on people's relationships, including their relationships with their families and society. The childhood stage plays a significant role in developing one's personality. It significantly affects the probabilities of achieving success in the future. Therefore, it is very important to conduct studies that target this age category and the developmental characteristics of children (Wazi and Yousif, 2013).

Many studies -e.g. Qwaider (2012); Sundus, (2018); Chaudron (2015)- suggest that children spend much time using electronic devices, like: mobile phone, TV, games, and etc.. Children use electronic devices for meeting various goals. For instance, they use electronic devices for playing games, watching videos, listening to songs, chatting with friends, and surfing various web pages. They spend most of their time doing these activities without paying attention to the screen brightness. They don't pay attention to the space between eyes and screen. That shall lead to experiencing several negative implications, such as: experiencing difficulties in concentrating, and eye irritation.

It should be noted that children today highly much on technologies (including smart devices) in various areas. Such areas include: the educational, and entertainment areas. Childhood plays a significant role in developing one's personality. It significantly affects the probabilities of achieving success in the future. Therefore, it is very important to conduct studies that shed a light on this age category and the developmental characteristics of children (Bahro, 2014).

The lower primary school stage is a very critical school stage in one's life. The ages of the children during the lower primary school are within the range of (6-12) years. During the lower primary school stage, the student enters school for the first time after being at home. His/her social relationships increase during this school stage. During this school stage, the child has various types of relationships with others and acquires new values and attitudes. During this school stage, he/she is capable of relying on himself/herself, and handling responsibility. 
During this school stage, he/she has more control over his/her emotions and shows more willingness to adopt new values. During this school stage, he/she is more willing to behave in accordance with the prevalent social traditions. (Qsaibat, 2007).

The child during the lower primary school stage shall is more independent from his/her mother in various areas. During this stage, the child is more energetic in terms of playing, running and jumping. During this school stage, he/she realizes that he/she is different from the children who are younger than him/her. During this school stage, he/she experiences difficulty in terms of establishing relationships with the ones who are older or younger than him/her (Khouri, 2000).

The use of the smart phone has many negative impacts on children. Al-Azam (2017) suggests that the excessive use of the smart phone has many negative impacts on the children's development in physical, cognitive, and social areas. He suggests that such excessive use has many negative impacts on children's imagination. The use of smart phones shall weaken the children's capability to concentrate. It shall make children lazy. It shall weaken children's social skills. Such skills may decline by a rate of 65\% (Omar and Othman, 2017).

The lower primary school stage is very critical school stage in one's life. During this stage, the child grows significantly in various areas. The events in this stage have impacts on the child in later stages. Much attention must be provided to the child during this stage in order to develop him/her in proper and healthy manner. It enables the child to think properly. It develops the child's behaviors. It involves regulating the way in which the child uses technologies, including smart devices (Shashtawi, 2005).

\section{Statement of the Problem}

Ikeda and Nakamura (2014) suggest that the number of smart phone users has been increasing dramatically during the past few years in all around the world. They suggest that this number shall increase dramatically in the future. Therefore, the present study proposes strategies that aim at reducing the extent of using smart devices by children. These strategies are proposed after reviewing the relevant theoretical literature and previous studies. It's necessary to propose such strategies. That is because the use of smart devices may lead to addiction or excessive use (Al-Rashem, 2012, Qwaider, 2013; Chaudron,2015; Sundus, 2018).

\section{The study's problem is represented in the following questions:}

- What is the reality of using smart devices by the public lower primary school studentsin Amman from the parents' perspective?

- $\quad$ Is there any statistically significant differences -at the statistical significance level of $(\mathrm{a}=0.05)$ - between the respondents' views which can be attributed to the (gender and age) of children?

\section{The study's objectives:}

This study aimed to:

1- Identify the advantages and disadvantages of using smart devices by the first, second and third grade students

2- $\quad$ Identify the extent of using smart devices by the public lower primary school students in Amman from the parents' perspective.

3- Identify whether there are statistically significant differences between the respondents' views which can be attributed to the (gender and age) of children?

\section{The Study's Significance:}

The present study is significant because it provides useful results for the following:

-Family: This study shall enrich parents' knowledge about the way of using smart devices properly by children.

-Schools: This study shall provide school management with strategies that aim at reducing the extent of using smart devices by public lower primary school students. These strategies shall raise the performance efficiency of students.

-Researchers: This study shall provide the researchers who want to conduct similar studies with a review for the relevant studies and theoretical literature. 


\section{Definition of terms:}

Smart devices: They refer to all the modern technological devices. They include: mobile phone, iPads, computers and etc.. (Al-Filali, 2012, 16).

Smart devices (operational definition): They refer to all the modern technological devices used by the public lower primary school students (i.e. 1 st grade- $6^{\text {th }}$ grade students) during the academic year 2019/2020 in public schools.

\section{The study's limits:}

Spatial limits: This study was conducted during the academic year 2019/2020 in public schools.

Temporal limits: This study was conducted at the public lower primary school in Amman

Human limits: This study sampled 384 parents of the public lower primary school students in Amman

\section{Previous Studies}

The researchers reviewed several studies

First: Studies in Arabic language

Wazi and Yousif (2013) aimed to explore the reality of using modern technologies and their impact on communication between parents and their children. They adopted a descriptive approach. They reviewed the relevant theoretical literature. It was found that the technology has serious impacts on people's lives, including the lives of children and teenagers. It was found that technology increases the gap of communication between parents and their children. It was found that technology increases decreases the extent of having family interaction. It was found that it's proper to prevent children and teenager from using technology in order to fight against the negative impacts of technology. In fact, technology must be used properly.

Abu Al-Rab and Al-Qsairi (2014) aimed to explore the behavioral problems resulting from the use of smart phones among children from the perspective of parents. A descriptive analytical approach was adopted. The latter researchers developed a questionnaire for collecting data. This questionnaire sheds a light on several areas; social, educational and psychological areas. The sample consists from 122 parents who were selected randomly. It was found that the most prevalent problems are the social problems followed by the educational and psychological problems respectively.

Al-Jamal (2014) aimed to explore the negative impacts of smart phones on students' behaviors from the perspective of principals and educational supervisors in the schools located in the Southern areas of Khalil. He adopted a descriptive analytical approach. He developed a twenty item questionnaire to collect data from respondents. He sampled $54.2 \%$ of the educational supervisors in the schools located in the Southern areas of Khalil. It was found that there smart phones have various negative impacts on students' behaviors from the perspective of principals and educational supervisors in the schools located in the Southern areas of Khalil.

Al-Azam (2017) aimed to explore the extent of using smart phones in the teaching-learning process. To meet the study's goals, the researcher used a descriptive approach. He used a survey to collect data. A questionnaire was used to collect data from 100 students. Those students were selected from private Jordanian universities during the academic year 2016/2017. They were majoring in instructional technology. It was found that the respondents' extent of using smart phones in the learning process is moderate. It was found that there are significant differences between the respondents' extent of using smart phones in the teaching-learning process which can be attributed to their gender.

\section{First: Studies in English language}

Chen (2013) conducted a study in China. He aimed to explore the extent of using smart devices by students outside school. He sampled 30 students whose ages are within the range of 20-17 years. The smart devices of the sampled students include applications for learning language. Those applications were used inside and outside the classroom. It was found that the smart devices play an effective role in learning language. That is because students enjoy using smart devices inside and outside the classroom.

George and Odgers (2015) aimed to explore the impacts of using mobile phones on teenagers' growth. They aimed to explore the impacts of the mobile phones on electronic violence, social development, teenagers' relationships, identity development and cognitive performance. They aimed to explore the impacts of the mobile 
phones on the relationships between parents and their child. A descriptive analytical approach was adopted. The latter researchers developed a questionnaire for collecting data. The questionnaire forms were distributed to 365 teenagers in Florida, USA. It was found that there are various impacts for the use of mobile phones by teenagers. For instance, such use may lead to the aggravation of the existent mental problems. It was found that using mobile phones has positive impacts on teenagers. . Such positive impacts include: developing the skills of shy teenagers.

Chaudron (2015) conducted a qualitative study in collaboration with academic partners in various European countries. He aimed to explore the reality of using modern technologies by children. He aimed to explore their families' experiences in this regard. He aimed to explore the way the children whose age is less than 8 years interact with the digital technologies, such as: smart phone, iPads, computers and electronic games. The sample consists from 70 families, and 119 children. It was found that most of the sampled children have skills in using digital technologies. Some of the sampled children have advanced skills in using digital technologies. . It was found that most of the sampled children don't have adequate awareness about the risks associated with using the digital technologies.

Sandus (2015) aimed to explore the negative and positive impacts of using modern technological devices on children. He aimed to explore the impact of smart devices on children's cognitive and motor skills in Pakistan. He aimed to explore the methods that can be used by parents for controlling and reducing their children's use of smart devices and ensuring that their children use smart devices in a good manner. A descriptive analytical approach was adopted. It was found that it's necessary to specify a specific time at which students are allowed to use smart devices, like smart phones. It was found that it's necessary to reduce the amount of time spent by children in using smart devices. Children shouldn't be allowed to use smart devices when this time ends.

Hosokawa and Katsura (2018) aimed to explore the relationship between using mobile technologies and adjustment among the early elementary school students. They used a questionnaire in order to collect data from parents. It was found that there is a significant relationship between using mobile technologies and adjustment among the early elementary school students. It was found that there is a significant relationship between using mobile technologies and experiencing behavioral problems among the early elementary school students.

$\mathrm{Ng}$ et al. (2017) aimed to explore the relationship between using smartphones and academic performance among the students enrolled in Malaysian universities. A questionnaire was used for collecting data from 176 university students in Malaysia. It was found that there is a significant negative relationship between using smartphones and academic performance among the students enrolled in Malaysian universities. In other words, the higher the use of smartphones, the lower the students' academic performance shall be.

Nath and Mukherjee (2015) aimed to explore the positive and negative effects of using smartphones. They collected data through reviewing the relevant studies. They found that there are many benefits gained from using smartphones. For instance, smart phones are used in the fields of communication, and entertainment. They can be used for accessing the latest news. They can be used for doing business presentations in business organizations. They can be used for doing homework. However, people may become addicted to the use of smartphones (Nath and Mukherjee, 2015).

\section{Comments on the aforementioned studies}

- $\quad$ The aforementioned studies shed a light on issues related to the use of smart devices. They shed a light on the positive and negative impacts of those devices on people including children. For instance, Sandus (2018) aimed to explore the negative and positive and negative impacts of modern technological devices on children. Al-Jamal (2014) aimed to explore the negative impacts of smart phones on students' behaviors from the perspective of principals and educational supervisors in the schools located in the Southern areas of Khalil. Wazi and Yousif (2013) aimed to explore the reality of using modern technologies and its impact on communication between parents and their children

There are differences between the aforementioned studies in terms of the areas they target. For instance, some studies shed a light on social areas, whereas other studies shed a light on educational areas. Other studies shed a light on the psychological areas,

There are differences between the aforementioned studies in terms of the population, and sample they target. For instance, the samples differ in terms of age category.

- $\quad$ Most of the aforementioned studies adopt descriptive analytical approach. Some of the aforementioned studies adopt descriptive approach 
The aforementioned studies provides the present study with information that enriches the theoretical framework. Such information enabled the researchers to develop the study's instrument

- $\quad$ The present study is different from the aforementioned studies in terms of the category it targets. For instance, it targets the public lower primary school students.

\section{The study's methodology:}

The researchers of the present study adopted two approaches. These approaches are:

a)- A descriptive approach: It involves several measures that aim at describing a specific phenomenon in an accurate and comprehensive manner. Such description is based on several facts and data. It is based on processing, classifying and analyzing data. Through these process, results can be concluded about the concerned phenomenon (Ateye, 2016). The latter approach is adopted by many researchers for offering readers a sensory description for things and items. It can be adopted to determine whether certain sensory attributes are deemed accepted or not. It may be adopted by researchers to explore variables and their dimensions and constituents (Lawless and Heymann, 1999).

b)- An inferential approach: It refers to the process of analyzing, and interpreting data in the aim of reaching results and conclusion. The data is collected from a sample selected from a population. This approach aims at making predictions and generalizations. It aims at describing a specific phenomenon or a problem in the aim of identify the reasons and factors associated with it (Al-Wadi and Al-Zu'bi, 2011).

\section{The Study's Population:}

The study's population consists from all the parents of the public lower primary school students in Amman. A cluster sample was selected from the study's population. The size of this population is considered big. The population was divided based on the directorates, and grades. Four directorates in Amman were selected randomly. 23 public schools were selected randomly. Out of each school, several school were selected randomly from the lower primary school stage. Thus, questionnaire forms were distributed to 384 public lower primary school students to be answered by their parents. The final sample consists from 384 parents of public lower primary school students.

\section{The study's instrument:}

A questionnaire was developed by the researchers. It was developed in a manner that fits with the study's variables. It was developed after reviewing the relevant studies. It consists from the following parts:

Part 1: This part aims to collect personal data from the respondents (i.e. the academic qualification of the head of household, average family income, child's gender, and child's age).

Part 2: This part aims to shed a light on the use of smart devices by the public lower primary school students. To be specific, it aims to identify the extent of spread of smart devices among the public lower primary school students (13 items). It aims to explore the extent of using smart devices by the public lower primary school students ( 7 items). It aims to explore the reasons of using smart devices by the public lower primary school students ( 8 items). It aims to explore the family's attitudes towards using smart devices by students ( 5 items). It aims to explore the attitudes of the people surrounding the students towards using smart devices by students (5 items).

The five point Likert scale was adopted. The scores of this scale are within the range of (1-5). They are presented in table (1)

Table (1): The scores of the five point Likert scale

\begin{tabular}{|l|l|l|l|l|}
\hline Strongly disagree & Disagree & Neutral & Agree & Strongly agree \\
\hline 1 & 2 & 3 & 4 & 5 \\
\hline
\end{tabular}

The categories used for classifying means were set based on the equation listed below: (Sekaran \& Bougie, 2012):

The interval $=$ (the maximum value- the minimum value) / the number of required categories The interval $=(5-1) / 3=1.33$ 
Based on the value of the interval, the following criteria were set for classifying means: High: higher than 3.66

Moderate: 2.34-3.66

Low: Lower than 2.34

Validity of the questionnaire:

To measure the validity of the questionnaire, the Cronbach alpha coefficient values are calculated. Such values must be 0.60 or higher in order to be deemed accepted(Sekaran \& Bougie, 2012).

Table (4): The Cronbach alpha coefficient values

\begin{tabular}{|l|r|r|}
\hline Variable & $\begin{array}{l}\text { The Cronbach } \\
\text { alpha } \\
\text { coefficient } \\
\text { value }\end{array}$ & $\begin{array}{l}\text { Number } \\
\text { of items }\end{array}$ \\
\hline $\begin{array}{l}\text { The extent of spread of smart devices among the public lower primary school } \\
\text { students }\end{array}$ & .925 & 13 \\
\hline $\begin{array}{l}\text { The extent of using smart devices by the public lower primary school } \\
\text { students }\end{array}$ & .874 & 7 \\
\hline $\begin{array}{l}\text { The reasons of using smart devices by the public lower primary school } \\
\text { students }\end{array}$ & .846 & 8 \\
\hline The family's attitudes towards using smart devices by students & .861 & 5 \\
\hline $\begin{array}{l}\text { The attitudes of the people surrounding the students towards using smart } \\
\text { devices by students }\end{array}$ & .901 & 5 \\
\hline Total & $\mathbf{. 9 0 5}$ & $\mathbf{3 8}$ \\
\hline
\end{tabular}

Based on table (4), it can be noticed that the values of Cronbach alpha coefficient are within the range of (0.9250.861). All these values are accepted because they are greater than 0.60 . The total value of Cronbach alpha coefficient is 0.905 . Thus, the questionnaire is reliable.

\section{The results related to the study's questions:}

\section{Results related to the first question:}

Q.1. What is the reality of using smart devices by the public lower primary school students in Amman from the parents' perspective?

To answer this question, means and standard deviations are calculated. These values are presented in table (5)

Table (5): The reality of using smart devices by the public lower primary school students in Amman from the parents' perspective

\begin{tabular}{|c|c|c|c|c|c|}
\hline Rank & No. & Variable & Mean & Std. & Level \\
\hline 1. & 5 & $\begin{array}{l}\text { The attitudes of the people surrounding the } \\
\text { students towards using smart devices by } \\
\text { students }\end{array}$ & 3.8078 & .67250 & High \\
\hline 2. & 1 & $\begin{array}{l}\text { The extent of spread of smart devices among } \\
\text { the public lower primary school students }\end{array}$ & 3.7993 & .44399 & High \\
\hline 3. & 3 & $\begin{array}{l}\text { The reasons of using smart devices by the } \\
\text { public lower primary school students }\end{array}$ & 3.7653 & .57850 & High \\
\hline 4. & 4 & $\begin{array}{l}\text { The family's attitudes towards using smart } \\
\text { devices by students }\end{array}$ & 3.7349 & .67991 & High \\
\hline \multirow[t]{2}{*}{5.} & 2 & $\begin{array}{l}\text { The extent of using smart devices by the public } \\
\text { lower primary school students }\end{array}$ & 3.5971 & .74894 & Moderate \\
\hline & Total & & 3.7475 & .48815 & \\
\hline
\end{tabular}

Based on table (6), the overall mean is 3.7475 . The total standard deviation is 0.48815 . The mean of the attitudes of the people surrounding the students towards using smart devices by students is ranked first. It is 3.8078 which is high. The mean of the extent of spread of smart devices among the public lower primary school students is ranked second. It is 7993 which is high. The mean of the reasons of using smart devices by the public lower primary school students is ranked third. It is 3.7653 which is high. The mean of the family's attitudes towards 
using smart devices by students is ranked fourth. It is 3.7349 which is high. The mean of the extent of using smart devices by the public lower primary school students is ranked fifth. It is 3.5971 which is moderate.

It was found that the lower primary school stage students highly prefer using smart devices (e.g. mobile phones, and iPad). It was found that the attitudes of the people surrounding the students towards using smart devices by students are positive. For instance, the family provides the child with the things he/she needs for using the smart device for playing games, watching videos or etc..

It was found that the extent of using smart devices by the public lower primary school students is high. That is because children tend to imitate the behaviors of their colleagues. Thus, some children use smart devices with paying less attention to the fulfillment of their duties and doing their homework. Some children use smart devices more than playing games that require physical movement. It was found that parents have positive attitudes towards using smart devices by their children.

\section{Results related to the second question}

Q.2. Is there any statistically significant differences - at the statistical significance level of $(a=0.05)$ - between the respondents' views which can be attributed to the (gender and age) of children?

To answer this question, the independent sample t-test was conducted. Through conducting this test, the researchers aimed to explore whether there are statistically significant differences between the respondents' views which can be attributed to the (gender) of children. In addition, the one way analysis of variance (ANOVA) was conducted aimed to explore whether there are statistically significant differences between the respondents' views which can be attributed to the (age) of children. Scheffe test was conducted to identify the ones whose the differences are for their favor. The results is this regard are presented below.

First: Results related to the statistically significant differences between the respondents' views which can be attributed to the (gender) of the child.

Table (6): The results of the independent sample t-test

\begin{tabular}{|r|r|l|l|r|r|r|l|}
\hline Gender & Frequency & Mean & \multicolumn{1}{l|}{ Std. } & $\begin{array}{l}\text { Calculated } \\
\text { t value }\end{array}$ & df. & Sig. & Result \\
\hline Male & 68 & 3.8991 & .53228 & 2.737 & 382 & 0.006 & Significant \\
\hline Female & 316 & 3.7068 & .52421 & & 382 & \\
\hline
\end{tabular}

Based on table (6), it appear that there are differences between the respondents' attitudes which can be attributed to gender of the child. To identify whether these differences are significant or not, the independent sample t-test. The calculated $t$ value is 2.737 which is significant. Thus, there are statistically significant differences -at the statistical significance level of $(\mathrm{a}=0.05)$ - between the respondents' views which can be attributed to the (gender) of children. The latter differences are for the favor of the parents of male children. The latter parents show more positive attitudes than the parents of female children. The latter result may be attributed to the fact that the features of smart devices attract males more than females. For instance, the games installed on smart devices attract male children more than female children.

Second: Results related to the statistically significant differences between the respondents' views which can be attributed to the (age) of the child

Table (7): The results of the one way analysis of variance (ANOVA)

\begin{tabular}{|l|r|r|l|l|l|l|}
\hline & $\begin{array}{l}\text { Sum of } \\
\text { squares }\end{array}$ & df & $\begin{array}{l}\text { Mean } \\
\text { square }\end{array}$ & $\begin{array}{l}\text { Calculated } \\
\text { f value }\end{array}$ & Sig. & Result \\
\cline { 1 - 5 } $\begin{array}{l}\text { Between } \\
\text { groups }\end{array}$ & $\mathbf{6 . 8 9 2}$ & $\mathbf{2}$ & $\mathbf{3 . 4 4 6}$ & $\mathbf{1 3 . 0 3 4}$ & 0.000 & Significant \\
\cline { 1 - 4 } $\begin{array}{l}\text { Within } \\
\text { groups }\end{array}$ & 100.723 & $\mathbf{3 8 1}$ & $\mathbf{2 0 6}$ & & \\
\cline { 1 - 4 } Total & 107.614 & $\mathbf{3 8 3}$ & & & \\
\hline
\end{tabular}

$(*)$ : This sign means that the value is statistically significant the statistical significance level of $(a=0.05)$

Based on table (7), it was found that the calculated $\mathrm{f}$ value is 13.034. This value is statistically significant at the statistical significance level of $(a=0.05)$. That means that there are statistically significant differences between the respondents' views which can be attributed to the (age) of children. To identify the ones whose the differences are for their favor. The results is this regard are presented below, the researchers conducted Scheffe test. The results of this test are presented in table (8) below: 
Table (8):The results of Scheffe test

\begin{tabular}{|c|c|c|c|c|}
\hline \multirow[t]{2}{*}{ Child's age } & & 6 -less than 8 years & 8 -less than 10 years & $\begin{array}{l}\begin{array}{l}10 \text {-less than } 12 \\
\text { years }\end{array} \\
\end{array}$ \\
\hline & 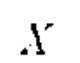 & 3.46 & 3.82 & 3.78 \\
\hline 6 -less than 8 & 3.46 & - & $-.3603 *$ & $-.3203 *$ \\
\hline 8 -less than 10 & 3.82 & - & - & .0400 \\
\hline 10-less than 12 & 3.78 & - & - & - \\
\hline
\end{tabular}

$(*)$ : This sign means that the value is statistically significant at the statistical significance level of $(a=0.05)$

Based on table (8),it was found that there are statistically significant differences between the respondents' views which can be attributed to the (age) of the child. The latter differences are attributed to the parents whose children's ages are within the range of (8-less than 10 years) \& the parents whose children's ages are within the range of (10-less than 12 years). That means that the latter parents have more positive attitudes than the parents whose children's ages are within the range of (6-less than 8 years).

\section{Conclusion:}

The researchers concluded the following:

- The attitudes of the people surrounding the students towards using smart devices by students are positive.

- The extent of spread of smart devices among the public lower primary school students is high

- $\quad$ The family's attitudes towards using smart devices by students are positive.

- The extent of using smart devices by the public lower primary school students is moderate.

In the light of the aforementioned results, it is necessary to provide parents with training courses about the proper use of smart devices by children. In addition, children's smart devices must be provided with programs that block improper websites. Teachers must promote awareness among students about the benefits of using smart devices.

\section{Recommendations}

In the light of the aforementioned results, the researchers proposed several strategies. These strategies that aim at reducing the extent of using smart devices by public lower primary school students. They are listed below:

1) The social interaction strategies:

A. The child should be integrated socially within the family:

That can be done through holding conversations with the child. It can be done through assigning tasks to the child that don't require the use of smart devices. It can be done through making the child spend much of his/her time with family. It should be noted that the use of smart devices for a long time shall make the child socially isolated.

B. Managing and controlling the time that the child spends on using smart devices.

The time dedicated for using the smart device by the child must be controlled by the family. Controlling this time shall make the student realize that it's not permitted to use smart devices at any time he/she desires. Thus, the child shall act on this basis.

C. Being open minded when dealing with children:

Being open minded when dealing with children play a significant role in fighting against the excessive use of smart devices by children. That is because being open minded shall make the parents identify the needs and interests of their child. That shall make the parents more capable of dealing and interacting with the child. Thus, the parents will become more capable of convincing the child about the serious disadvantages of smart devices and the way of avoiding these impacts. They will become more capable of convincing the child about the advantages of these devices and the way of attaining them.

Being open minded when dealing with the child shall increase the child's trust in his/her parents. Thus, the child will become more capable of expressing his/her views in front of his/her parents about the use of smart devices

2) Promoting awareness by the school about the use of smart devices: 
School, family and the surrounding people play a significant role in controlling the way of using smart devices by children. Through school, teachers can guide the children about the way of using smart devices properly. Teachers can also provide students with knowledge about the advantages and disadvantages of using smart devices.

3) Promoting awareness through curricula about the advantages and disadvantages of using smart devices: School should play a significant role in controlling the use of smart devices by children. That can be done through controlling the way smart devices are used in courses.

\section{References:}

Abu Al-Rab, Mohammad and Al-Qsairi, Elham (2014). The behavioral problems associated with using smart phones among children from the parents' point of view in light of some variables. The International Journal for Educational Research. 35(15)

Bahro, Sumaya Bader Al-Deen (2014). The early childhood stage- child psychology. The United Kingdom. The Arab British Academy for Higher Education.

Al-Jamal, Sameer, Sulaiman (2014).The negative impacts of smart phones on students' behaviors from the perspective of principals and educational supervisors in the schools located in the Southern areas of Khalil- The directorate of education- the Southern areas of Khalil- Open Quds University-Dora branch

Khouri, George (2000). The psychological aspect of the growth of children and teenagers. Beirut, Al-Mu'asase Al-Jame'eye Lederasat. P.57

Al-Rashem, Maryam Jabbar (2012). The information and communication technology and its impact on social security: A social field study in Baghdad University. Alustath Journal. 2 (221).

Shashtawi, Hisham Mohammad (2005). The developmental characteristics of kindergarten children. The Journal of Risalet Almu'alem- Jordan. 43(2), 21-41

Al-Azam Naji(2017). The extent of using smart phones in the teaching-learning process: A field study from the perspective of the students majoring in technology education at the private Jordanian universities. Unpublished MA thesis. The Middle East University. Amman. Jordan.

Ateye, Muhsen Ali (2016). Scientific research in education: methodologies, instrument and statistical means. $2^{\text {nd }}$ edition. Al-Manahej publication and distribution house. Amman. Jordan

Omar, Salemand Othman, Khaleefah (2017). The electronic games and their impact on the social skills development during childhood. The Educational Journal. Issue (50).

Qsaibat, Su'ad (2007). The developmental psychology (Childhood and adolescence). Cairo. Maser Lil Ketab publication and distribution house.

Qwaider, Maryam (2013). The impact of electronic games on children's behaviors: A descriptive analytical study targeting students in Algeria, Unpublished MA thesis. Algeria University

Wazi, Tawoos and Yousif, Adel (2013. The modern technologies and their impact on communication between parents and their children: (Internet and mobile phones as models). The second international conference on communication and quality of life in family. University of Ouargla. Algeria.

Chaudron. S. (2015) Young Children (0-8) and Digital Technology. A qualitative exploratory study across seven countries. Institute for the Protection and Security of the Citizen, Report EUR 27052 EN.

Chen, Y. (2013). Extending family to school life: college students use of the mobile phone. Human-Computer Studies, 67, 179-191.

George, M. and Odgers, C. (2015). Seven fears and the Science of How Mobile Technologies May Be Influencing Adolescents in the Digital Age. Perspectives on Psychological Science, 10(6), 832-851.

Ikeda, K. and Nakamura, K. (2014). Association between mobile phone use and depressed mood in Japanese adolescents: a cross-sectional study. Environ Health Prev Med, 19: 187-193.

Sekaran, U., \& Bougie, R., (2012). Research Methods for Business: A Skill Building Approach. (6 ${ }^{\text {th }}$ ed), NY: John Wiley \& Sons Inc, New York. 
Sundus M. (2018) The Impact of using Gadgets on Children. Journal of Depression and Anxiety. 7, 1.

Lawless H.T., and Heymann H. (1999) Descriptive Analysis. In: Sensory Evaluation of Food. Food science text series. Springer, Boston, MA

Hosokawa, R. and Katsura, T. (2018). Association between mobile technology use and child adjustment in early elementary school age. PLOS One Journal. 13(7).d

Ng, S.; Hassan, N.; Nor, N.; and Malek, N. (2017). The Relationship Between Smartphone Use and Academic Performance: A Case of Students in a Malaysian Tertiary Institution. Malaysian Online Journal of Educational Technology. 5(4)

Nath, A. and Mukherjee, S. (2015). Impact of Mobile Phone/Smartphone: A pilot study on positive and negative effects. International Journal of Advance Research in Computer Science and Management Studies. 3(5).

\section{Acknowledgement:}

The researchers would like to thank the respondents who participated in the present study. 